\title{
Ndc80 Loop as a protein-protein interaction motif
}

\author{
Ngang Heok Tang ${ }^{*}$ and Takashi Toda
}

\begin{abstract}
Our understanding of the structure and function of kinetochores has advanced dramatically over the past 10 years, yet how the plus end of spindle microtubules interacts with the kinetochore and establishes amphitelic attachment for proper sister chromatid segregation remains unresolved. However, several recent reports from different organisms have shed new light on this issue. A key player in microtubule-kinetochore interaction is the conserved Ndc80 outer kinetochore complex. In both yeast and human cells in particular, a ubiquitous internal 'loop' found in the Ndc80 molecule interrupting its C-terminal coiled-coil domain plays critical roles in protein-protein interaction, by recruiting microtubule-binding proteins to ensure proper kinetochore-microtubule attachment. In this commentary, we summarise the recent progress made and discuss the evolutionary significance of this loop's role in microtubule dynamics at the kinetochore for accurate chromosome segregation.
\end{abstract}

Keywords: Kinetochore, Ndc80/Hec1 complex, Spindle microtubule, Loop, Cdt1, Dam1 complex, Ska complex, TACC-TOG, Humans, Yeast

\section{Background}

During mitosis, the kinetochore complex attaches to the mitotic spindle to ensure accurate chromosome segregation [1-3]. The Ndc80/Hec1 complex, which is part of the KMN network (the KNL1/Mis12 complex/Ndc80 complex), is composed of a heterotetramer consisting of Ndc80/Hec1, Nuf2, Spc24 and Spc25 [1,4]. This complex is situated in the outer kinetochore and directly interacts with the microtubule $[2,5]$. However until recently, how the kinetochore establishes stable amphitelic attachment to the dynamic plus end of the spindle microtubule during mitotic progression remained largely unknown.

\section{Main text and discussion}

\section{The Ndc80 loop and its binding partners}

Structural studies have revealed that the Ndc80 complex has a dumbbell-like architecture consisting of an internal rod-shaped coiled-coil structure and a globular domain on each end $[4,5]$. In addition, a ubiquitous loop exists that interrupts the middle of the coiled coil domains. This loop was suggested to play a structural role in kinetochore geometry and/or the tension-sensing mechanism, yet its precise function at the molecular level

\footnotetext{
* Correspondence: Ngang-Heok.Tang@cancer.org.uk; takashi.toda@cancer.org.uk Laboratory of Cell Regulation, Cancer Research UK, London Research Institute, Lincoln's Inn Fields Laboratories, 44 Lincoln's Inn Fields, London
} WC2A 3LY, UK remained elusive for some time [6]. Recent studies from several laboratories have started to uncover its precise role $[7,8]$.

By using specific $n d c 80$ mutants that contain mutations within the loop in Saccharomyces cerevisiae, the Tanaka lab showed that this region facilitates binding of the Dam1 kinetochore complex to the Ndc80 complex (Figure 1, left). This binding is essential for the conversion of lateral microtubule binding to end-on binding, which is a prerequisite for proper chromosome segregation [9]. Two other studies using mammalian (HeLa) cell lines unveiled the roles of the Ndc80 internal loop in recruiting the Ska (Ska1) kinetochore complex and the Cdt1 replication licensing protein (Figure 1, right) $[10,11]$; The Nilsson lab showed that in cells with the Ndc80 loop deleted or artificially reversed, lateral attachment could be formed, but proper end-on attachment failed to be established. This defect seemed largely due to the displacement of the Ska complex from the kinetochore [11]. On the other hand, the Cook and Salmon labs used a clever synchronise-release technique to uncover novel roles of the Cdt1 protein in mitotic progression upon the completion of S phase [10]. Intriguingly, Cdt1 localises to the kinetochore during early mitosis and appears to directly interact with the Ndc80 loop based upon various binding analyses. Unlike the Dam1 and Ska complexes however, no microtubule-binding

\section{Biomed Central}

(c) 2013 Tang and Toda; licensee BioMed Central Ltd. This is an Open Access article distributed under the terms of the Creative Commons Attribution License (http://creativecommons.org/licenses/by/2.0), which permits unrestricted use, distribution, and reproduction in any medium, provided the original work is properly cited. 


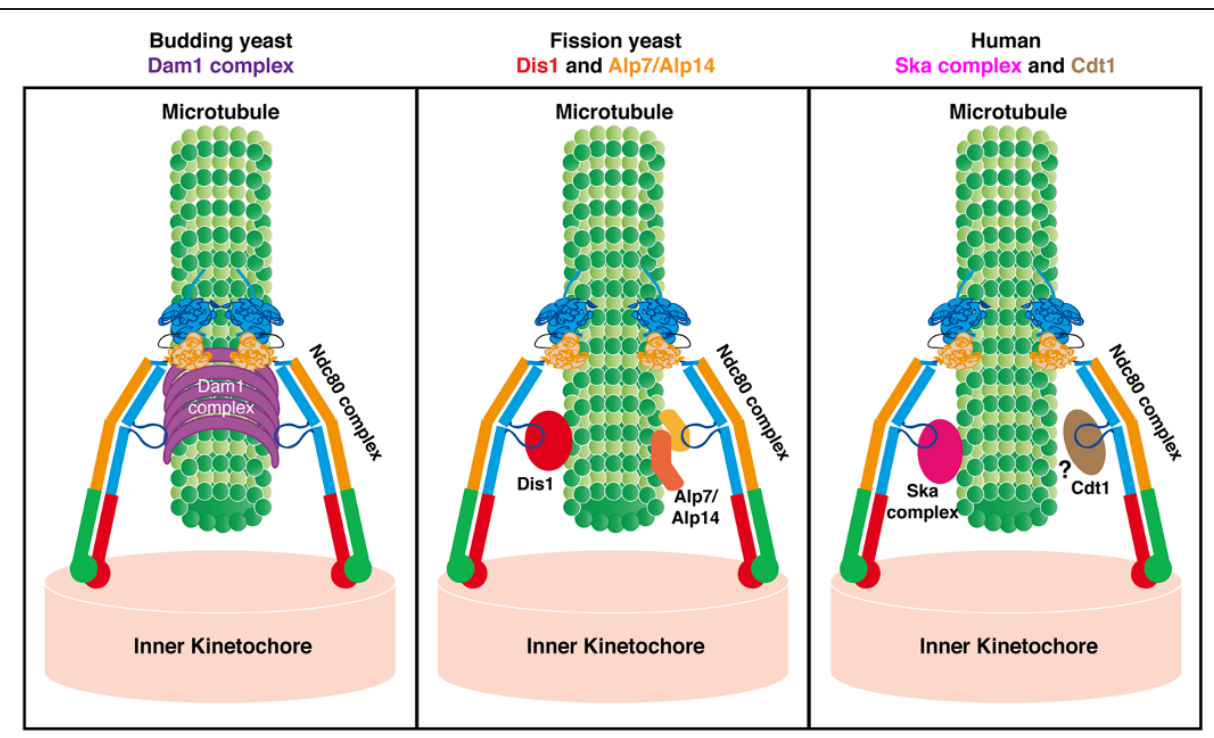

Figure 1 The Ndc80 internal loop plays distinct roles in kinetochore-microtubule attachment by recruiting multiple regulatory factors to the outer kinetochore. In budding yeast, the Ndc80 loop helps to recruit the Dam 1 complex to the outer kinetochore (left); whilst in fission yeast, the Ndc80 loop binds to and recruits the Dis1/TOG and Alp7/TACC-Alp14/TOG complexes (centre). In higher eukaryotes, the Ndc80 loop has been shown to be able to recruit the Cdt1 protein and the Ska complex, either directly or indirectly (right). Note that no microtubule-binding activity has been reported for the Cdt1 protein (depicted by ?). We suggest that the $\mathrm{Ndc80} \mathrm{loop} \mathrm{plays} \mathrm{a} \mathrm{role} \mathrm{in} \mathrm{protein-protein} \mathrm{interaction} \mathrm{to}$ ensure proper kinetochore-microtubule attachment.

activity has been shown for the Cdt1 protein. This makes it intriguing to look for possible microtubule associated proteins (MAPs) that Cdt1 interacts with on the kinetochores.

\section{Sequential binding of two TOG-TACC microtubule- associated proteins to the fission yeast $\mathrm{Ndc80}$ loop}

Our recent studies in Schizosaccharomyces pombe have uncovered that the $\mathrm{Ndc} 80$ internal loop binds to the Dis1/XMAP215/TOG and Alp7/TACC-Alp14/TOG MAP complexes (Figure 1, centre) [12,13]. In the ndc8021 mutant (in which a mutation in the loop region, L405P, is largely responsible for the phenotype), the Dis1 protein delocalises from the kinetochore, resulting in an unstable mitotic spindle and early mitotic arrest with no stable kinetochore-microtubule attachment being observed in this mutant [13]. Interestingly, we identified another $n d c 80$ loop mutant with a different mutation site in the loop (F420S), that showed normal Dis1 protein localisation to the kinetochore and normal mitotic spindle structure. In this mutant however, the Alp7Alp14 complex was specifically delocalised from the kinetochore, leading to chromosome missegregation during anaphase A [12]. We speculate that in fission yeast, via the interaction with two different TOG (and TACC) proteins, the Ndc80 loop plays sequential roles in ensuring proper kinetochore-microtubule attachment and chromosome segregation. Binding of the Dis1 protein to the Ndc80 loop in early mitosis, which is independent of microtubules [14], is important for mitotic spindle assembly and stabilisation, whilst subsequent binding of the Alp7-Alp14 complex, which requires spindle microtubules [15], ensures proper anaphase progression.

\section{Roles of the Ndc80 loop in microtubule dynamics at the kinetochore}

Microtubules are intrinsically dynamic and bind to a cohort of MAPs. In particular, the mitotic spindle changes its polymerising/depolymerising activity throughout the different stages of mitosis. This leads us to suggest that the Ndc80 internal loop, by interacting with different proteins during different stages, helps to regulate microtubule dynamics. It would be interesting to test this idea by reconstituting each protein complex in the presence of microtubules in vitro.

To date, all the Ndc80 loop-interacting proteins identified have no reported microtubule depolymerising activity. Although the Dam1 and Ska complexes have been shown to track on the plus end of depolymerising microtubules and the TOG proteins are in fact microtubule polymerases, it remains enigmatic as to how microtubule depolymerisation per se is directionally driven during anaphase A [16,17]. It should also be of note that whether the Dam1 and the Ska complexes interact with the loop remains to be established $[16,18]$. Therefore, how the kinetochores remain attached to the depolymerising microtubule plus-ends during anaphase remains a major question to be answered. 


\section{Conclusions}

Although the proteins bound to the Ndc80 loop in different organisms show no sequence homology to one another, these studies showed the importance and capabilities of the Ndc80 internal loop region as a proteinprotein interaction motif, thereby ensuring proper chromosome segregation, and that mitotic progression is conserved from yeasts to higher eukaryotes. Furthermore, these studies provided further insight into how the kinetochore, in particular the Ndc80 complex, regulates microtubule dynamics during mitosis.

\section{Abbreviations}

MAP: Microtubule-associated protein; TACC: Transforming acidic coiled coil; +TIP: Plus-end tracking protein; TOG: Tumor overexpressed gene.

\section{Competing interests}

The authors declare that they have no competing interests.

\section{Authors' contributions}

NHT and TT jointly wrote the paper. Both authors read and approved the final manuscript.

\section{Acknowledgements}

We thank Dr. Yuzy Matsuo for preparation of Figure 1. This work was supported by Cancer Research UK (T.T.).

Received: 8 March 2013 Accepted: 8 March 2013

Published: 15 March 2013

\section{References}

1. Takeuchi K, Fukagawa T: Molecular architecture of vertebrate kinetochores. Exp Cell Res 2012, 318:1367-1374.

2. DeLuca JG, Musacchio A: Structural organization of the kinetochoremicrotubule interface. Curr Opin Cell Biol 2012, 24:48-56.

3. Cheeseman IM, Desai A: Molecular architecture of the kinetochoremicrotubule interface. Nat Rev Mol Cell Biol 2008, 9:33-46.

4. Ciferri C, Pasqualato S, Screpanti E, Varetti G, Santaguida S, Dos Reis G, Maiolica A, Polka J, De Luca JG, De Wulf P, et al: Implications for kinetochore-microtubule attachment from the structure of an engineered Ndc80 complex. Cell 2008, 133:427-439.

5. Cheeseman IM, Chappie JS, Wilson-Kubalek EM, Desai A: The conserved KMN network constitutes the core microtubule-binding site of the kinetochore. Cell 2006, 127:983-997.

6. Wang HW, Long S, Ciferri C, Westermann S, Drubin D, Barnes G, Nogales E: Architecture and flexibility of the yeast $\mathrm{Ndc} 80$ kinetochore complex. J Mol Biol 2008, 383:894-903.

7. Nilsson J: Looping in on Ndc80 - How does a protein loop at the kinetochore control chromosome segregation? Bioessays 2012, 34:1070-1077.

8. Varma D, Salmon ED: The KMN protein network - chief conductors of the kinetochore orchestra. J Cell Sci 2012, 125:5927-5936.

9. Maure JF, Komoto S, Oku Y, Mino A, Pasqualato S, Natsume K, Clayton L, Musacchio A, Tanaka TU: The Ndc80 loop region facilitates formation of kinetochore attachment to the dynamic microtubule plus end. Curr Biol 2011, 21:207-213.

10. Varma D, Chandrasekaran S, Sundin LJR, Reidy KT, Wan X, Chasse DAD Nevis KR, DeLuca JG, Salmon ED, Cook JG: Recruitment of the human Cdt1 replication licensing protein by the loop domain of $\mathrm{Hec} 1$ is required for stable kinetochore-microtubule attachment. Nature Cell Biology 2012, 14:593-603.

11. Zhang G, Kelstrup CD, Hu XW, Kaas Hansen MJ, Singleton MR, Olsen JV, Nilsson J: The Ndc80 internal loop is required for recruitment of the Ska complex to establish end-on microtubule attachment to kinetochores. Journal of Cell Science 2012, 125:3243-3253.

12. Tang NH, Takada H, Hsu KS, Toda T: The internal loop of fission yeast Ndc80 binds Alp7/TACC-Alp14/TOG and ensures proper chromosome attachment. Mol Biol Cell 2013. doi:10.1091/mbc.E12-11-0817.
13. Hsu KS, Toda T: Ndc80 Internal loop interacts with Dis1/TOG to ensure proper kinetochore-spindle attachment in fission yeast. Curr Biol 2011, 21:214-220

14. Nakaseko Y, Goshima G, Morishita J, Yanagida M: M phase-specific kinetochore proteins in fission yeast: microtubule-associating Dis1 and Mtc1 display rapid separation and segregation during anaphase. Curr Biol 2001, 11:537-549.

15. Sato M, Vardy L, Angel Garcia M, Koonrugsa N, Toda T: Interdependency of fission yeast Alp14/TOG and coiled coil protein Alp7 in microtubule localization and bipolar spindle formation. Mol Biol Cell 2004, 15:1609-1622.

16. Schmidt Jens C, Arthanari H, Boeszoermenyi A, Dashkevich Natalia M, Wilson-Kubalek Elizabeth M, Monnier N, Markus M, Oberer M, Milligan Ron A, Bathe M, et al: The kinetochore-bound Ska1 complex tracks depolymerizing microtubules and binds to curved protofilaments. Developmental Cell 2012, 23:968-980.

17. Lampert F, Hornung P, Westermann S: The Dam1 complex confers microtubule plus end-tracking activity to the $\mathrm{Ndc} 80$ kinetochore complex. J Cell Biol 2010, 189:641-649.

18. Lampert F, Mieck C, Alushin GM, Nogales E, Westermann S: Molecular requirements for the formation of a kinetochore-microtubule interface by Dam1 and Ndc80 complexes. J Cell Biol 2013, 200:21-30.

doi:10.1186/1747-1028-8-2

Cite this article as: Tang and Toda: Ndc80 Loop as a protein-protein interaction motif. Cell Division 2013 8:2.

\section{Submit your next manuscript to BioMed Central and take full advantage of:}

- Convenient online submission

- Thorough peer review

- No space constraints or color figure charges

- Immediate publication on acceptance

- Inclusion in PubMed, CAS, Scopus and Google Scholar

- Research which is freely available for redistribution 